Uclés Ramada, G. (2021): El uso de ¿no? en España y México. Un estudio intergenérico a partir de corpus.

Cultura, Lenguaje y Representación, Vol. xxv, 305-327

ISSN $1697-7750 \cdot$ E-ISSN 2340-4981

DOI: http://dx.doi.org/10.6035/clr.2021.25.17

\title{
El uso de ¿no? en España y México. Un estudio intergenérico a partir de corpus
}

The use of ¿no? in Spain and México. An intergeneric corpus-based study

\author{
GLORIA UCLÉS RAMADA
}

UNIVERSITAT DE VALÈNCIA

ORCID: https://orcid.org/0000-0001-8564-809X

Artículo recibido el / Article received: 2020-11-01

Artículo aceptado el / Article accepted: 2021-01-06

RESUMEN: En este artículo se presentan los valores que la forma ¿no? puede desarrollar y se proporciona una comparación entre su comportamiento en el español de España y en el de México en dos géneros discursivos diferentes: conversación y entrevista. Para ello, se lleva a cabo un análisis a partir de los corpus Val.Es.Co. 2.0 y Ameresco-Monterrey para la conversación y PRESSEA Madrid, Valencia, Monterrey y Ciudad de México para la entrevista. La tipología de ¿no? puede dividirse en dos grupos: las funciones que implican la gestión de la imagen (petición de afiliación, atenuación, intensificación) y las que se dedican a la estructuración de la información (delimitación, movilización de respuesta). El estudio contrastivo muestra tanto diferencias distribucionales asociadas al género $y$, en el caso de la entrevista, al papel discursivo como a la variedad diatópica.

Palabras clave: ¿no?, marcadores del discurso, atenuación, intensificación, afiliación

ABSTRACT: In this paper, the functions of the Spanish discourse marker $i n o$ ? are described and a comparative analysis with data from Mexico and Spain in two different discursive genres is carried out. To do so, the following corpora are analysed: Val.Es.Co. 2.0 and Ameresco-Monterrey conversation corpora and samples of the cities of Valencia, Madrid, Monterrey and Mexico City from the sociolinguistics interviews corpus PRESEEA. Results show that the functions of ¿no? can be split in two groups: those devoted to face management (request for affiliation, mitigation and boosting) and those related to information structure (response mobilisation and delimiting boundaries). The contrastive analysis 
shows that some differences in the distribution of the data can be ascribed to the genre or, in interviews, to the discursive role, whereas certain combinations of functions can be linked to dialect preferences.

Key words: ¿no?, discourse markers, mitigation, boosting, affiliation.

\section{INTRODUCCIÓN}

En este artículo se presentan los valores pragmáticos que ¿no? puede desarrollar y se proporciona una comparación entre su comportamiento en el español de España y en el de México en dos géneros discursivos diferentes: conversación y entrevista. El estudio desde una óptica interdialectal e intergenérica de este marcador del discurso permite explorar si estas dos variables afectan a su comportamiento y, en el caso de que sea así, determinar de qué forma y en qué medida el género discursivo y el dialecto inciden en su distribución de esta forma. Para ello, se emplea una tipología de funciones de ¿no? basada en los valores relacionados con la gestión de la imagen de este marcador (Uclés, 2020c) y en sus funciones como estructurador de la información.

Dado que este marcador cuenta formalmente con una base interrogativa, resulta pertinente contrastar su uso en géneros donde la interacción tiene un papel preeminente. La conversación, y especialmente la coloquial, es el género interactivo por excelencia. Siguiendo la descripción de Briz (1998) se trata de un evento cara a cara, que sucede en el aquí y el ahora, cooperativa, con una toma de turno no predeterminada y una alternancia de turnos dinámica. Sin embargo, aunque se pueda considerar el género naturalmente interactivo, la interacción no es un fenómeno exclusivo de este género. El hecho de que la entrevista sociolingüística suceda en presencia física, de manera sincrónica y que pueda ser más o menos cooperativa con las intervenciones del interlocutor contribuye a que se produzca cierto grado de interacción, a pesar de la existencia de una toma de turnos pautada y una alternancia de turnos más rígida. Uno de los rasgos más significativos para el análisis que se presenta corresponde al hecho de que "cada participante posee un rol estático, no se pueden intercambiar los papeles de entrevistador y entrevistado" (Albelda, 2004: 112). Estos dos papeles discursivos dentro de la entrevista tienen comportamientos distintos y, por tanto, se estudian por separado en el análisis de los datos.

Por otra parte, la mayoría de los estudios sobre este marcador se han llevado a cabo partiendo de datos del español peninsular (véase sección 2). Emplear datos de corpus de la variedad peninsular y el español de México que resulten contrastables establece las bases para poder llevar a cabo un análisis comparativo. Así pues, las conclusiones no se restringen al estudio de un dialecto y un género en concreto, sino que, por una parte, permiten obtener una visión más amplia del comportamiento de ¿no? y, por otra, posibilitan discernir qué parte de su distribución puede adscribirse al género y cuál parece estar constreñida por el dialecto.

\section{LOS ESTUDIOS SOBRE ¿NO?}

Gran parte de la bibliografía dedicada a ¿no? trata este marcador como parte de un conjunto de formas más o menos amplio que comparte unos rasgos comunes. Otro aspecto que parece gozar de gran estabilidad en este tipo de trabajos lo representa el amplio grado de acuerdo a la hora de identificar dos valores: el comprobativo (Ortega Olivares, 1985; Fuentes, 1990; Santos Río, 2003; García Vizcaíno, 2005; Montañez, 
2008, 2015; Fuentes, 2009; Rodríguez Muñoz, 2009; Móccero, 2010) y el fático (Fuentes, 1990; Santos Río, 2003; García Vizcaíno, 2005; Montañez, 2008, 2015; Fuentes, 2009; Rodríguez Muñoz, 2009; Móccero, 2010; Santana, 2017). Así pues, de todas estas obras se desprende que ¿no? forma parte de un grupo de elementos que bien cumplen una función apelativa o fática. Existen, sin embargo, trabajos que han transcendido dicha categorización y presentan una tipología de funciones más compleja (Cestero, 2003; Fuentes y Brenes, 2014; Cestero, 2019), como se detalla en la Tabla 1.

Tabla 1. Tipología de funciones reconocidas para ¿no? en Cestero (2003), Fuentes y Brenes (2014) y Cestero (2019)

\begin{tabular}{|c|c|c|}
\hline Cestero, 2003 & Fuentes y Brenes, 2014 & Cestero, 2019 \\
\hline $\begin{array}{l}\text { - } \text { Búsqueda de ratificación de } \\
\text { acuerdo } \\
\text { - Constatación } \\
\text { entendimiento } \\
\text { - Énfasis }\end{array}$ & $\begin{array}{l}\text { - Asegurar la recepción } \\
\text { - Asegurar la corroboración } \\
\text { del interlocutor } \\
\text { - Reafirmación de la opinión } \\
\text { propia } \\
\text { - Modal que apoya otro } \\
\text { modal } \\
\text { - Dar paso al rema } \\
\text { - Focalizador } \\
\text { - Apoya una corrección }\end{array}$ & $\begin{array}{l}\text { - Búsqueda de ratificación de } \\
\text { acuerdo } \\
\text { - Constatación } \\
\text { entendimiento } \\
\text { - Búsqueda de ratificación de } \\
\text { acierto } \\
\text { - Justificador }\end{array}$ \\
\hline
\end{tabular}

Respecto a la procedencia de los datos, la mayoría de los estudios en los que se han realizado desde la perspectiva del español peninsular, a excepción de Móccero (2010) quien utiliza datos de Buenos Aires, San Martín (2011) que se basa en entrevistas de PRESEEA de Santiago de Chile y Santana (2017) que realiza un estudio multidalectal. En cuanto al género empleado existe una mayor variación en el origen de los datos. Gran parte de los estudios se centran en un solo género, como la conversación (Montañez, 2008, 2015; Móccero, 2010), la entrevista sociolingüística (Fuentes, 1990; San Martín, 2011; Santana, 2017; Cestero, 2019) y el lenguaje parlamentario (Fuentes y Brenes, 2014), mientras que se documenta un único caso (Cestero, 2003) en tratan datos procedentes de la conversación y del discurso académico. Existen también trabajos que se basan en corpus de referencia como el CREA (Fuentes, 2009; Rodríguez Muñoz, 2009) y el COREC (García Vizcaíno, 2005) o que no cuentan con datos de corpus (Ortega Olivares, 1985; Santos Río, 2003).

\section{METODOLOGÍA}

En este trabajo se pretende presentar una descripción completa de los valores que puede adoptar la forma ¿no? y emplear esta tipología para llevar a cabo un estudio comparativo que permita observar los patrones de uso en el español de España y de México. Para llevar a cabo estos objetivos, se ha trabajado con corpus correspondientes a los dos países y a dos géneros discursivos distintos: la conversación y la entrevista. El hecho de incluir dos géneros, uno prototípicamente interactivo como lo es la conversación y otro más periférico - por su preparación y por el fin transaccional o informativo- como la entrevista, permite presentar una panorámica más amplia de los valores de este marcador, así como evitar un posible sesgo de los datos derivado de considerar las características propias de este marcador a partir de un solo género discursivo. Así pues, se ha escogido el corpus Val.Es.Co. 2.0 (Valencia, España) y el corpus Ameresco- 
Monterrey (Monterrey, México) para la conversación y para la entrevista se emplea una muestra del corpus PRESEEA en las ciudades de Madrid y Valencia para España y Ciudad de México y Monterrey para México. En este corpus de trabajo se han filtrado las ocurrencias de ¿no? y se han anotado en una base de datos según la tipología de sus funciones que se presenta más adelante (sección 4). Como las muestras de los corpus seleccionados cuentan con frecuencias diferentes de palabras (Tabla 2), se han estandarizado los datos para poder realizar comparaciones y se proporciona la frecuencia por cada mil palabras. Los gráficos que se presentan en el artículo se han realizado con el programa R (R Core Team, 2019) y, específicamente, con el paquete ggplot2 (Wickham, 2016).

Tabla 2. Número de palabras de los corpus empleados

\begin{tabular}{|c|c|c|}
\hline Corpus & \multicolumn{2}{|c|}{ Número de palabras } \\
\hline Val.Es.Co. 2.0 & \multicolumn{2}{|c|}{89483} \\
\hline Ameresco Monterrey & \multicolumn{2}{|l|}{89185} \\
\hline \multirow[b]{2}{*}{ PRESEEA España (muestra) } & \multicolumn{2}{|l|}{99749} \\
\hline & $\begin{array}{l}\text { Entrevistado } \\
81460\end{array}$ & $\begin{array}{l}\text { Entrevistador } \\
18289\end{array}$ \\
\hline \multirow[b]{2}{*}{ PRESEEA México (muestra) } & \multicolumn{2}{|l|}{135670} \\
\hline & $\begin{array}{l}\text { Entrevistado } \\
111230\end{array}$ & $\begin{array}{l}\text { Entrevistador } \\
24440\end{array}$ \\
\hline
\end{tabular}

\section{LOS VALORES DE ;NO?}

En estudios anteriores desarrollados para el español de España se ha tratado en profundidad el papel que el marcador ¿no? lleva a cabo en relación con la gestión de protección de las imágenes de los participantes en la interacción. Concretamente, se ha estudiado su función como estrategia de atenuación (Uclés, 2020a), así como de intensificación y afiliación (Uclés, 2020c). El presente trabajo tiene como objetivo describir de forma completa los valores de ¿no?, así como realizar un análisis comparativo de su distribución en el español de España y de México en distintos géneros discursivos. Así pues, además de los resultados obtenidos en los trabajos anteriores, se incluyen las funciones asociadas con estructuración de la información y el valor de ataque de la imagen en la función intensificadora.

El Gráfico 1 representa una muestra esquemática de la tipología de funciones de ¿no? que se propone. Como se puede ver, existe una primera subdivisión entre los valores asociados a la gestión de la imagen y los de la estructuración de la información. Dentro de la gestión de la imagen, nos encontramos, por una parte, con que -mediante la atenuación y la intensificación- ¿no? lleva a cabo las funciones orientadas de protección de la imagen de autoprotección y la prevención, así como también indica la petición de la afiliación. Por otra parte, la intensificación también puede emplearse como una estrategia de ataque a la imagen. En cuanto a las funciones de estructuración de la información se distingue el uso de esta forma como movilizador de respuesta y como delimitador. 


\section{Gráfico 1. Propuesta de tipología para las funciones de ¿̨no?}

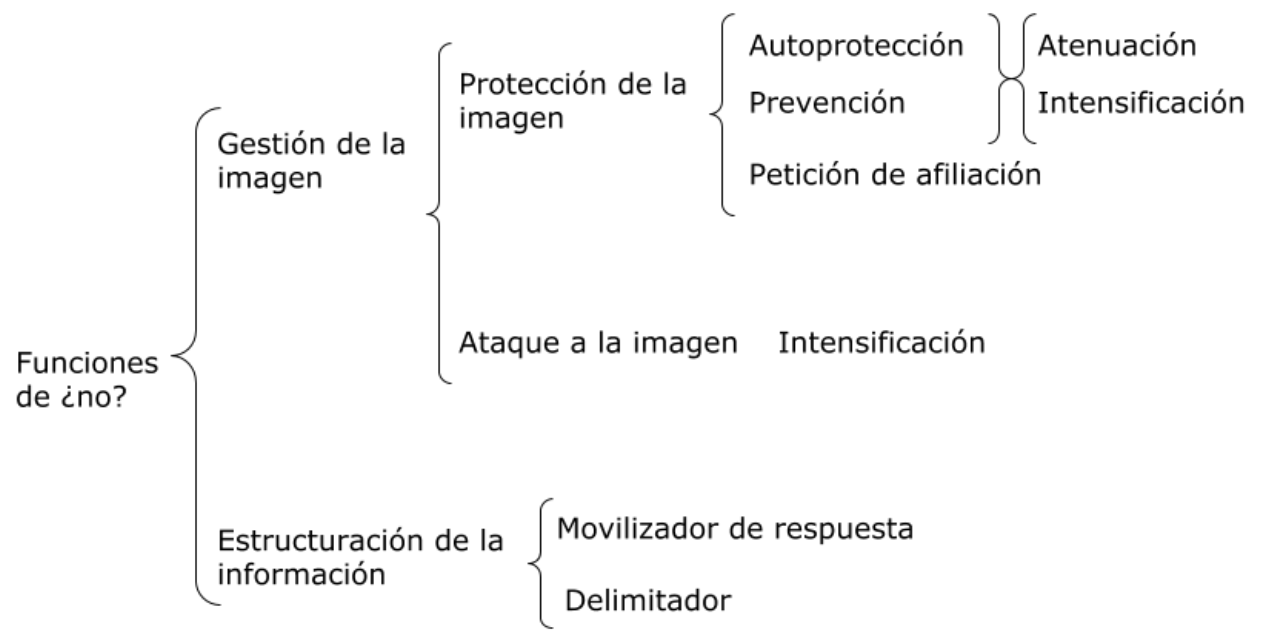

\subsection{FUNCIONES DE GESTIÓN DE LA IMAGEN}

Como se muestra en el Gráfico 1, una parte sustancial de las funciones atribuidas a ¿no? corresponden con valores dedicados a la gestión de la imagen de los participantes en la interacción. Concretamente se identifican la atenuación, la intensificación y la petición de afiliación como funciones que protegen la imagen. Como se verá a continuación, la atenuación y la intensificación pueden desarrollar valores de autoprotección de la imagen o prevención y, por tanto, el hecho de identificar atenuación excluiría directamente la posibilidad de que se produjera un uso intensificador a la vez y viceversa. La petición de afiliación, sin embargo, puede usarse en conjunción con estos dos valores.

\subsubsection{Atenuación}

El uso de ¿no? con valor atenuante está ampliamente documentado en la bibliografía (Ortega Olivares, 1985; García Vizcaíno, 2005; Montañez, 2008, 2015; Landone, 2010; Brenes, 2011; Fuentes y Brenes, 2014; Uclés, 2017, 2018, 2020a, 2020c; Cestero, 2019). En este trabajo, para identificar la atenuación en las muestras del corpus, se sigue la definición operativa propuesta por Estellés y Albelda (en prensa), en la que se concibe como un fenómeno basado en tres dimensiones: la lingüística, la social y la cognitiva. Así pues, la perspectiva lingüística debe manifestarse a través de una estrategia concreta por la que se materialice la atenuación, desde la perspectiva social este fenómeno busca un beneficio para los hablantes -generalmente relacionado con la protección de las imágenes implicadas- $\mathrm{y}$, por último, en el plano cognitivo intenta evitar que la concepción que el hablante cree que los participantes en la interacción tienen de este pueda modificarse, cuando dicho cambio no se ajusta con la idea que quiere proyectar el hablante. Como se indica en los valores de ¿no?, la atenuación puede aplicarse para conseguir un fin de protección de la propia imagen del hablante (ejemplo 1) o para prevenir posibles daños en la imagen de otros interlocutores (ejemplo 2).

A partir de los datos procedentes de nuestro corpus, encontramos en el ejemplo (1) una muestra de autoprotección de la imagen a través la atenuación. El hablante está explicando a los interlocutores en qué consisten las oposiciones para profesorado de secundaria en lengua y literatura española. Sin embargo, esta persona no tiene información de primera mano porque aún no se ha involucrado en el proceso. Así pues, 
transmite la experiencia de terceros (eso es lo que han conta(d)o loos los colegas que se han presentao ¿no?). Por tanto, al no poder constatar la veracidad o exactitud de lo que relata recurre a estrategias atenuantes para proteger su propia imagen, en este caso materializadas por el uso de ¿no? Desde la perspectiva cognitiva, hablar sobre un tema que no conoce y sobre el que solo se ha obtenido información de segunda mano puede, en este sentido, poner en peligro la imagen que B cree que proyecta en sus interlocutores.

(1) B: ((en)) lengua y literatura pero ijolines! / ¡son ((unoos)) unos bestias! / ¡setenta y dos temas! y ahíi quee // pues bueno yo no tengo ni idea de oposiciones ¿no? eso es lo que han conta(d)o loos los colegas que se han presentao ¿no? así ¿no? con bolas / te salen tres bolas $\uparrow / /$ como si fuera el bingo $\uparrow \S$

(Corpus Val.Es.Co. 2.0, Conversación 42)

El ejemplo (2) refleja un uso atenuante de ¿no? con el fin de prevenir daños en la imagen de otro interlocutor distinto al que lo produce. Los hablantes A y B están planeando cómo celebrar el cumpleaños de una amiga común, Ania Karenina. En la línea 04, A reitera la necesidad de organizar algún tipo de celebración para su amiga, pero esta movilización a la acción se ve rebajada por el uso de ¿no? con una función atenuante que rebaja el grado de imposición de su intervención. De esta manera, resulta más probable que se acepte la propuesta de A de hacer algo y, además (perspectiva social), evita aparecer ante su interlocutor como una persona controladora e impositiva (perspectiva cognitiva).

(2) $01 \mathrm{~B}$ : ¿qué le vamos a hacer a <anónimo $>$ Ania Karenina</anónimo $>$

02 A: sí es cie<alargamiento/>rto

03 B: no le he preguntado a $<$ alargamiento/ $><$ anónimo $>$ Dana $<$ anónimo $>$

04 A: pero hay que hacerle algo ¿no?

05 B: ¿pero como qué?

$06 \mathrm{~A}:$ hum $<$ alargamiento/> icomprarle un pastel?

$07 \mathrm{~B}:$ no $<$ alargamiento/ $>$ no se va a comer el pastel $/(0,8)$ no le gusta el pastel

(Corpus Ameresco-Monterrey, MTY_043_02_15)

\subsubsection{Intensificación}

La función intensificadora de ¿no? se encuentra recogida las referencias de Cestero (2019) y Uclés (2020c). Sin embargo, como se expone con más detalle más adelante (sección 5.2.1), la incidencia de este valor es muy reducida, lo que podría explicar su escasa representación en la bibliografía. En un trabajo anterior centrado en explorar el papel de ¿no? en la gestión de la imagen (Uclés, 2020c), se identificaba su papel como estrategia de protección de la imagen (ejemplo 3). En el presente análisis de ¿no? también se reconoce su uso como estrategia de amenaza de la imagen (ejemplo 4). La definición operativa que se sigue para la intensificación corresponde a la propuesta por Albelda (Albelda, 2007; 2014), que la considera la expresión del mayor grado en una escala subjetiva creada por los hablantes.

En el ejemplo (3) se puede observar una muestra de la función intensificadora empleada con el fin de proteger la propia imagen de la hablante. En este fragmento C, que es la pareja de B, regaña a este por no haber calentado el café. Ante esta intervención, B se considera injustamente atacado (línea 05, a míi ((lo que)) me gusta es que no me regañen). Tras pedir una clarificación, la hablante $\mathrm{A}$-madre de $\mathrm{B}-\mathrm{se}$ defiende de lo que percibe como un cambio de la percepción de los interlocutores hacia ella, ya que, como progenitora de $\mathrm{B}$, tiene el papel de educar y reñir a su hijo en caso de que sea conveniente $\mathrm{y}$, por tanto, intenta cambiar la idea de que ha regañado constantemente a B (línea 08, hombre $\downarrow$ cualquiera diría que se pasan la vida regañándote ¿no?). 
(3) 01: C: $\S$ ¿CALIÉNTATELO $\downarrow !$ ¿NO TE LO VAS A CALENTAR? estamos con toda la movida del microondas $\uparrow$ y ahora va y se lo toma frío el tío $\uparrow$ moniato// 02 A: chica

$03 \mathrm{~B}$ : me lo calentaré porque me estás gritando

04 A: ¿pero a ti te gusta frío o caliente?

05 B: a míi ((lo que)) me gusta es que no me regañen $\S$

06 A: §te gusta ¿QUÉ?§

07 B: §QUE NO me regañen $\S$

08 A: §que no te regañen $\downarrow / /$ hombre $\downarrow$ cualquiera diría que se pasan la vida regañándote ¿no?//

(Corpus Val.Es.Co. 2.0, Conversación 9)

Un uso de ¿no? intensificador como ataque a la imagen se pude encontrar en el ejemplo (4). En este fragmento A y B están hablando sobre un conocido de A con el que tuvo algún tipo de relación amorosa. Concretamente, A sentencia que ya no está interesada en esa persona (línea 07, no si yo paso de ese ya), tras lo que se suceden una serie de turnos en los que esta hablante intenta convencer de este hecho a $\mathrm{B}$ al encontrar resistencia en sus respuestas irónicas (líneas 08 a 11). Finalmente, en la línea 12, B intensifica su intervención mediante el empleo de ¿no? (y voy yo y me lo creo ¿no?), que resalta el desacuerdo con A y supone un ataque a su imagen, ya que muestra abiertamente que no cree que su interlocutora esté diciendo la verdad.

(4) $01 \mathrm{~A}$ : no sé yo que le he hecho

02 B: ese/ eh gilipollas $\S$

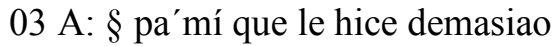

$04 \mathrm{~B}$ : esoo $\uparrow$ / quedó tan satisfecho que ahora le da miedo Lis $\uparrow$

05 A: ESTA ME COME OTRA VEZ $\uparrow$ (RISAS)

06 B: tú tranquila ¿eh? / no te preocupes es que el pobre aún $\rightarrow$

$07 \mathrm{~A}$ : no si yo paso de ese ya

$08 \mathrm{~B}$ : sí claro

09 A: ss / va en serio ¿eh?

$10 \mathrm{~B}:{ }^{\circ}(\text { va en serio })^{\circ} /$ sí sí

11 A: paso de él $\uparrow$

12 B: y voy yo y me lo creo ino?

$13 \mathrm{~A}$ : bueno dejemos el asunto ¿vale?§

(Corpus Val.Es.Co. 2.0, Conversación 33)

\subsubsection{Solicitud de afiliación}

Otra de las funciones con las que se asocia el uso de $¿ n o$ ? corresponde con su uso para solicitar afiliación. En palabras de Stivers (2008: 35), la afiliación se define como un fenómeno en el que "the hearer displays support of and endorses the teller's conveyed stance". Tal y como se entiende este concepto desde el análisis de la conversación, la afiliación supone una respuesta a un estímulo concreto: el posicionamiento (stance). Como se detalla con mayor profundidad en otro estudio (Uclés, 2020c), se considera que en los casos en los que ¿no? acompaña un posicionamiento adopta la función de remarcar a los interlocutores la necesidad de producir una respuesta afiliativa; es decir, actúa como una solicitud de afiliación. La solicitud de afiliación puede emplearse como única función relacionada con la gestión de la imagen (ejemplo 5) pero aparece también frecuentemente en conjunción con un uso atenuante (ejemplo 6).

En el ejemplo (5) A y B están hablando sobre una tercera persona no presente en la conversación que es compañera de clase de B. La hablante A intenta convencer a su interlocutora de que es más competente que su compañera de clase (línea 01). A asiente 
(línea 02), pero B insiste en recalcar su posición (línea 03). En la última intervención de A, responde volviendo a confirmar que es mejor que su compañera, pero esta vez lo acompaña con ¿no? (no/y lo sél ¿no? o sea sé que soy mejor que ella). Se considera que este es uso responde a una petición de afiliación de A a B. En este contexto, es probablemente la falta de confianza que muestra B previamente ante la respuesta de A lo que provoca que esta hablante demande explícitamente afiliación a su interlocutora sobre el posicionamiento que expresa de saberse mejor que su compañera.

(5) $01 \mathrm{~B}$ : que o sea que/ que puedes ser// mucho mejor que ella/ si es que ella es algo 02 A: sí

$03 \mathrm{~B}:$ ¿sí me entiendes?/// entonces

04 A: no/ y lo sé/ ¿no? o sea sé que soy mejor que ella

(Corpus Ameresco-Monterrey, MTY $015 \quad 02$ 15)

El ejemplo (6) corresponde a una secuencia argumentativa que se extiende durante varios tunos en los que la entrevistada valora cómo el malgasto de agua en su región puede acarrear consecuencias negativas en el futuro. El posicionamiento de la entrevistada es de alarma y preocupación ante la indiferencia de la población. Las instancias de ¿no? resaltadas en negrita tienen un componente de petición de afiliación. La entrevistada defiende que, salvo excepciones, la sociedad no es consciente del derroche de un bien escaso como lo es el agua, idea para la que solicita afiliación. Además de la función de petición de afiliación, se emplea la atenuación como estrategia para proteger de una posible amenaza a la imagen de la entrevistadora. En esta intervención, la entrevistada presupone un nivel de concienciación de la comunidad universitaria (yo creo que nada más / ustedes que están allá en la facultad sí se dan cuenta / ¿no? y porque lo están viendo / ¿no?) a la cual pertenece la entrevistadora, pero no la entrevistada. Esto puede percibirse como invasivo y, por tanto, I atenúa también con el uso de ¿̨no? con el fin de prevenir que la entrevistada pueda pensar que es una persona entrometida o que habla de realidades que desconoce.

(6) 01 I: ahorita la gente todavía no está consciente de / de la situación que está pasando / yo creo que nada más / ustedes que están allá en la facultad sí se dan cuenta / ¿no? / de / de que están estos problemas / está esto / está lo otro / porque lo están viendo / ¿no? / pero la gente que estamos / del otro lado // qué fácil / ¿no? / lavar la banqueta con la manguera $/<$ simultáneo $>$ como el de enfrente $</$ simultáneo $>$

(MEXI_M22_060)

\subsection{FUNCIONES DE ESTRUCTURACIÓN DE LA INFORMACIÓN}

El marcador ¿no? no solo se emplea asociado a valores que gestionan la interacción, sino que también cumple funciones de estructuración de la información, lo que se corresponde con lo que la bibliografía reconoce como el valor formulativo (Montañez, 2008; 2015). Para este estudio se identifican dos funciones generales que puede llevar a cabo esta forma en el ámbito de la estructuración de la información: la movilización de respuesta y la delimitación.

\subsubsection{Movilizador de respuesta}

Dentro de este grupo, se encuentran las instancias en las que ¿no? se utiliza como estrategia orientada a imponer mayor presión en los interlocutores para que produzcan una respuesta (Stivers y Rossano, 2010). Se distinguen dos maneras distintas mediante las cuales esta forma intenta buscar una respuesta. Por una parte, este elemento se añade al contenido anterior sin pausa previa de manera en la que convierte todo el fragmento 
sobre el que tiene ámbito al modo interrogativo (ejemplo 7). Por otra parte, también se detectan casos en los que se añade al final de una intervención después de una pausa larga (ejemplo 8). De esta manera, en el primer caso se trata de un elemento que transforma formalmente el segmento anterior al modo interrogativo, mientras que en el segundo caso la adición post hoc de ¿no? que no implica cambios en la modalidad, sino que realza la necesidad de que reciban una respuesta por parte de los interlocutores. En este sentido, el funcionamiento dual de ¿no? como movilizador de respuesta refrenda la propuesta Stivers y Rossano (2010: 29), quienes consideran que "the term question, which vernacularly characterizes an action, is in fact an omnibus term that expresses the institutionalization of response mobilization". Así pues, existen estrategias lingüísticas que ejercen mayor presión en el interlocutor para que produzca una respuesta. Se rechaza, pues, la idea de subsumir forma y función y se propone un modelo más complejo basado en la actividad comunicativa que pretende comunicar y en vez de en la modalidad del enunciado.

(7) I: en Doctor Esquerdo / $<$ simultáneo $>$ giras un poquito a mano derecha $</$ simultáneo $>$ E: $<$ simultáneo $>$ a mano derecha $</$ simultáneo $>$ después de Mar $<$ palabra_cortada/ $>$ $<$ vacilación $>>$ Marqués de Zafra ¿no?

I: claro / en Ma $<$ palabra_cortada/ $><$ vacilación/ $>$ en Marqués de Zafra

(MADR_M13_018)

(8) 279 P: pues no// pues noo tiene que estar tan tranquilo// ${ }^{\circ}(\text { ¿sabes? })^{\circ} / / /$ pues/ mala respuesta $\downarrow$ has dao// ¿no?

280 D: ya/ porque no $\uparrow \S$

281 P: $\S$ tú le has hecho esa pregunta $\uparrow$ y el debería haber respondido $\S$

282 D: § no me da tranquilidad

(Corpus Val.Es.Co. 2.0, Conversación 15)

\subsubsection{Delimitador}

El marcador ¿no? delimita de forma explícita el final de segmentos del discurso que se pueden considerar una unidad. La función delimitadora que ejerce esta forma, por tanto, se entiende como valor general que puede indicar la conclusión de elementos de diferente naturaleza. El modelo de segmentación de unidades de la conversación del Grupo Val.Es.Co. $(2003$; 2014) resulta una herramienta adecuada para establecer el tipo de unidades que delimita ¿no?, como lo corroboran los estudios de Montañez con este mismo marcador $(2008,2015)$ así como para otras formas (Montañez, 2009; 2015). En esta misma línea, se encuentran casos en los que ¿no? delimita el final de un acto (ejemplo 9), así como de un discurso al acompañar la conclusión del discurso directo (ejemplo 10).

En adición a la segmentación en unidades del discurso que proporciona el modelo de Val.Es.Co., en ocasiones se ha detectado que ¿no? delimita casos de incisos, como se muestra en el ejemplo (11) cuando el hablante vuelve sobre una información que ya ha mencionado anteriormente y que considera relevante repetir en la intervención en la que se enmarca. También se encuentra seguido de la expresión del posicionamiento (sección 4.1.3), tal y como aparece en el ejemplo (12) en el que, en la línea 05, la hablante B produce una valoración (bueno pues es normal ¿no?) que representa su posicionamiento respecto a lo que ella misma relata en la línea 01. 
(9) A: [vale $\downarrow] /$ cinco convocatorias y resuelta que-si por ejemplo/ el examen de matemáticas $\downarrow$ que no me voy a- que es el único que no me voy a presentar $\downarrow$ que es el día treinta de este mes aparte de que ese día hay otro también/ yo no me voy a presentar porque no tengo ni profesor ni nada $\uparrow$ y- y paso $\downarrow$ ino? / entonces yo esa convocatoria la pierdo $\downarrow$

(Corpus Val.Es.Co. 2.0, Conversación 13)

(10) I: a cada rato / entonces se / se echaron a perder muchas plantas / y le dijimos y / $<$ cita $>$ no importa / díganme / y yo voy otra vez $</$ cita $>$ ino? / y otra vez las trajo / y sí / entonces // pues sí // con eso hizo la tesis [...]

(MEXI_H23_018)

(11) I: no / ha sido toa la vida $<$ alargamiento/ $><$ vacilación $/>$ / mi abuelo / ya te he dicho antes que tenía mucha afición a los toros ino? / y<alargamiento/ $><$ vacilación/ $>$ / la ganadería de Machancoses

(VALE_H12_042)

(12) 01 B: [y ayer vino la] $/(0,3)$ ayer vino la $/(0,7)$ encargada y estábamos

$02 \mathrm{~A}:$ ah

03 B: § como $/(0,3)$ maquinitas ahí

04 A: $<$ risas $/>/(1,2)<$ risas $/>/(0,3)<$ ininteligible $/>$

$05 \mathrm{~B}$ : que es un poco<alargamiento/ $/(1,4)$ como digamos $/(2,1)$ bueno pues es normal ¿no?

06 A: ajá

(Corpus Ameresco-Monterrey, MTY_045_03_15)

\section{EL USO DE ¿NO? EN ESPAÑA Y MÉXICO}

En esta sección se estudia el empleo del marcador ¿no? según la variedad diatópica y el género discursivo. En primer lugar, en la sección 5.1 se detalla el uso de este marcador en las conversaciones y entrevistas españolas y mexicanas sin discriminar por valores. A continuación, en la sección 5.2 se examina la distribución de ¿no? a partir de una tipología de funciones previamente establecida (sección 4). La sección 5.2.1 se dedica a las funciones relacionadas con la gestión de la imagen, mientras que en 5.2.2 se profundiza en las funciones de estructuración de la información.

\subsection{LA DISTRIBUCIÓN DE ¿NO? EN ESPAÑA Y MÉXICO}

En esta sección se examina la distribución de la frecuencia total de aparición de ¿no? en España y México según los dos géneros discursivos analizados. Dado que el tamaño de las muestras para cada país y género es variable, la frecuencia se ha normalizado a partir de la aparición de esta forma por cada mil palabras. De esta manera, en la FIGURA 1 se compara la frecuencia de oucrrencias en la conversación en los datos de México y España y en la FIGURA 2 se recogen los datos de la entrevista, en los que en la frecuencia total se distingue la cantidad aportada por los entrevistados y los entrevistadores.

Figura 1. Frecuencia de ¿no? en la conversación por cada 1000 palabras 


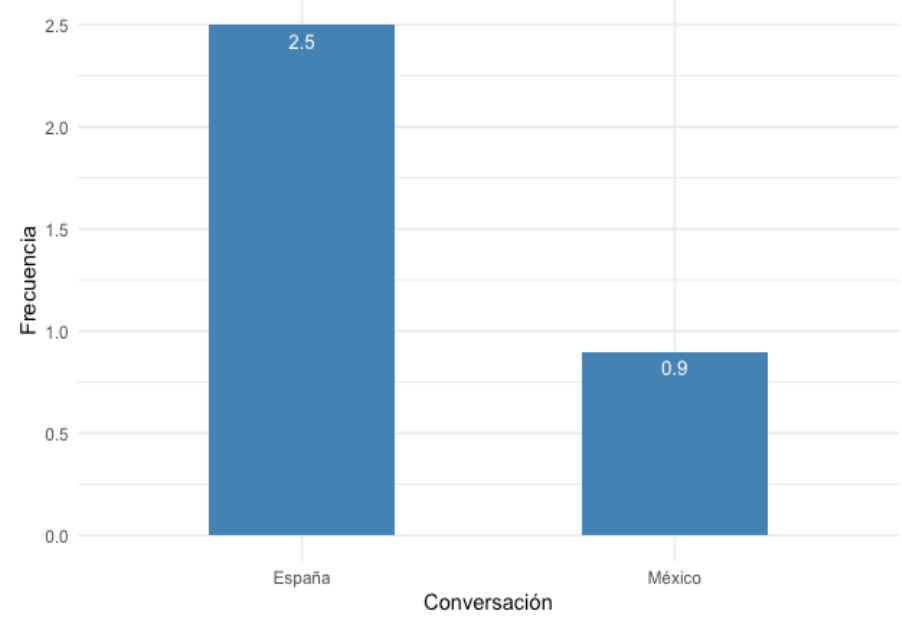

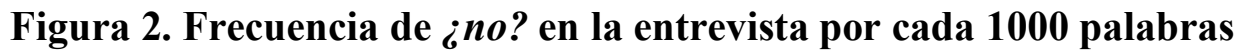

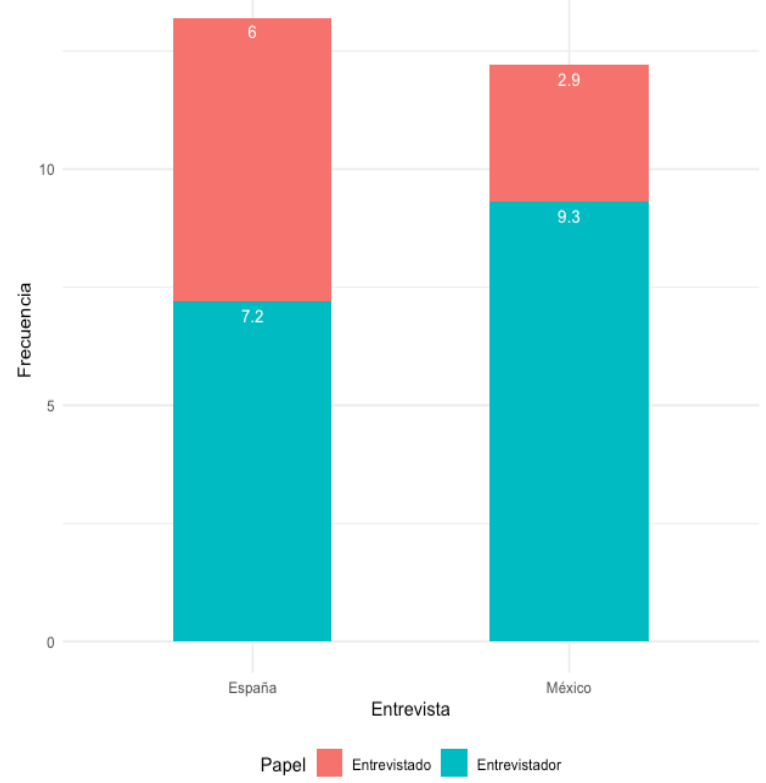

Como se puede apreciar a simple vista al comparar ambas figuras, el uso de ¿no? en España respecto a México resulta holgadamente mayor en la conversación y ligeramente superior en la entrevista. Pese a que en ambos países este marcador se multiplica su presencia en los datos de la entrevista respecto a los de la conversación, cabe señalar que el caso de México tiene un mayor impacto, puesto que el aumento alcanza una frecuencia más de diez veces mayor $(0,9$ veces por cada mil palabras en conversación y 12,2 en entrevista). Por su parte, en España el incremento es más modesto: 2,5 ocurrencias en conversación frente a 13,2 en entrevista. Al diferenciar los papeles discursivos en la entrevista, se detecta un patrón similar en ambas variedades diatópicas. Los entrevistadores usan ¿no? con mayor frecuencia que los entrevistados. De hecho, en el caso de México la frecuencia por cada mil palabras es algo más de tres veces superior (2,9 en entrevistados frente a 9,3 en entrevistadores). En España se mantiene esta misma tendencia pero con unas cifras más ajustadas (por cada mil palabras ¿no? aparece 6 veces en entrevistados y 7,2 en entrevistadores). Puesto que los datos se han normalizado para tener una base común con la que poder realizar un análisis comparativo, cabe señalar que 
tanto en las entrevistas de España como en las de México el número de palabras de los entrevistadores es mucho más reducido que el de los entrevistados. Por tanto, la acumulación de este marcador en el papel del entrevistador es todavía más llamativo.

\subsection{LA DISTRIBUCIÓN DE ¿¿NO? EN ESPAÑA Y MÉXICO SEGÚN LAS FUNCIONES}

En esta sección se realiza un análisis cuantitativo que contrasta los datos de México y España en los géneros de conversación y entrevista según las funciones establecidas para ¿no? Dada la complejidad de los datos, los resultados se dividen en dos apartados. En primer lugar, se presentan los datos de las funciones de gestión de la imagen y la interacción de estos valores entre sí. En segundo lugar, se muestran los datos de las funciones de estructuración de la información que puede desarrollar esta forma.

\subsubsection{Gestión de la imagen}

En este apartado se describen los resultados obtenidos del análisis del corpus respecto a la distribución de las funciones de gestión de la imagen. Para ello se comparan los datos de México y España en la conversación y la entrevista, en la que a su vez se distingue entre el comportamiento de ¿no? en el papel del entrevistador y el entrevistado. Como se ha expuesto anteriormente (sección 4.1), la atenuación y la petición de afiliación pueden aparecer, respectivamente, bien como único valor relacionado con la gestión de la imagen o utilizarse conjuntamente. Puesto que en el análisis de ¿no? estas dos funciones representan el mayor grado de interacción dentro de la gestión de las imágenes, las figuras 3, 4 y 5 muestran las relaciones entre atenuación y petición de afiliación en la conversación, en entrevistados y en entrevistadores. Dadas las limitadas ocurrencias de intensificación y su comportamiento tanto como elemento de protección y ataque a la imagen, este valor se trata por separado.

La FIGURA 3 muestra, para la conversación de España y México, el número de casos en los que la protección de la imagen (mediante atenuación) y la petición de afiliación se cruzan. En el caso de España, se puede observar una distribución más equilibrada de los datos respecto a México en los diferentes cruces de funciones. En la conversación española, la petición de afiliación se concentra como única estrategia y, en menor medida, asociada a la autoprotección. La intersección entre la ausencia de protección de la imagen y de afiliación acumula una suma elevada de casos. En cuanto a las combinaciones más empleadas en las variables ligadas a la protección de la imagen, las funciones de autoprotección y prevención sin componente afiliativo representan una parte notable del número total de los casos. Por su parte, en la conversación en México, el grueso de los datos corresponde a la ausencia de funciones de gestión de la imagen. La petición de afiliación, al igual que en los datos correspondientes a España, resulta más frecuente como único valor de gestión de la imagen, seguido de su uso en conjunción con la prevención. Sin embargo, cabe señalar que, cuantitativamente, el empleo de la petición de afiliación en los datos de conversación mexicana es limitado. Respecto a las funciones de protección de la imagen sin petición de afiliación, se observa que tanto la autoprotección como la prevención tienen un uso reducido. 
Figura 3. Relación entre la atenuación y la petición de afiliación en la conversación

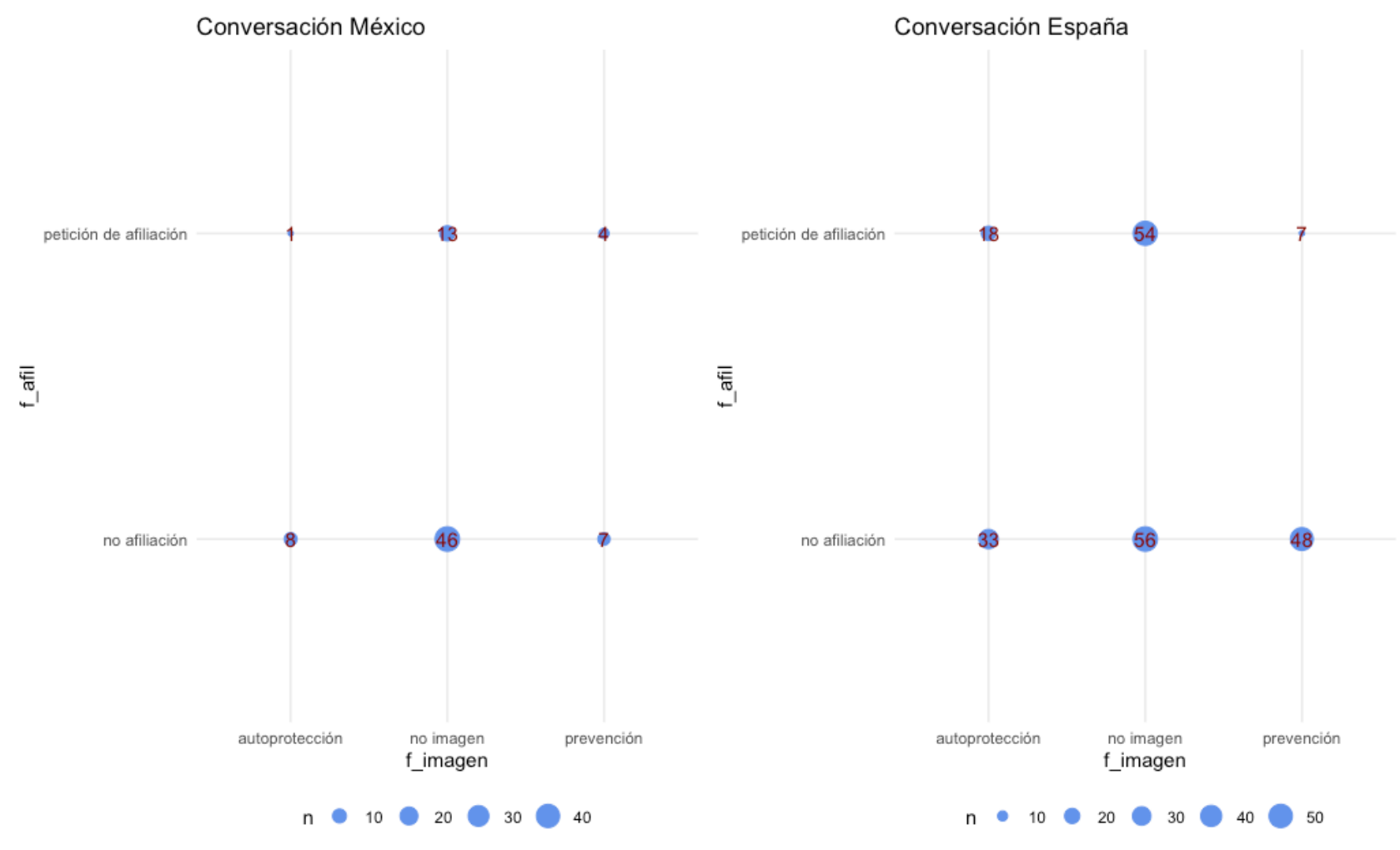

El uso de ¿no? dirigido a la protección en el papel del entrevistado en México y en España (FIGURA 4) presenta una distribución similar. En ambas variedades, la ausencia de un componente afiliativo y atenuante, así como la petición de afiliación sin imagen resultan ser las combinaciones más empleadas. Sin embargo, los datos de los entrevistados de España muestran una tendencia mayor a la petición de afiliación como único valor de gestión de la imagen o acompañado de la autoprotección. Respecto los atenuantes de ¿no?, se reporta un uso mucho más limitado en ambas variedades. Los datos muestran un empleo de la autoprotección en España más elevado que en México, mientras que la prevención cuenta con escasas ocurrencias (tanto acompañada de petición de afiliación como siendo función de gestión de la imagen única) en los dos países. 


\section{Figura 4. Relación entre la atenuación y la petición de afiliación en entrevistados}

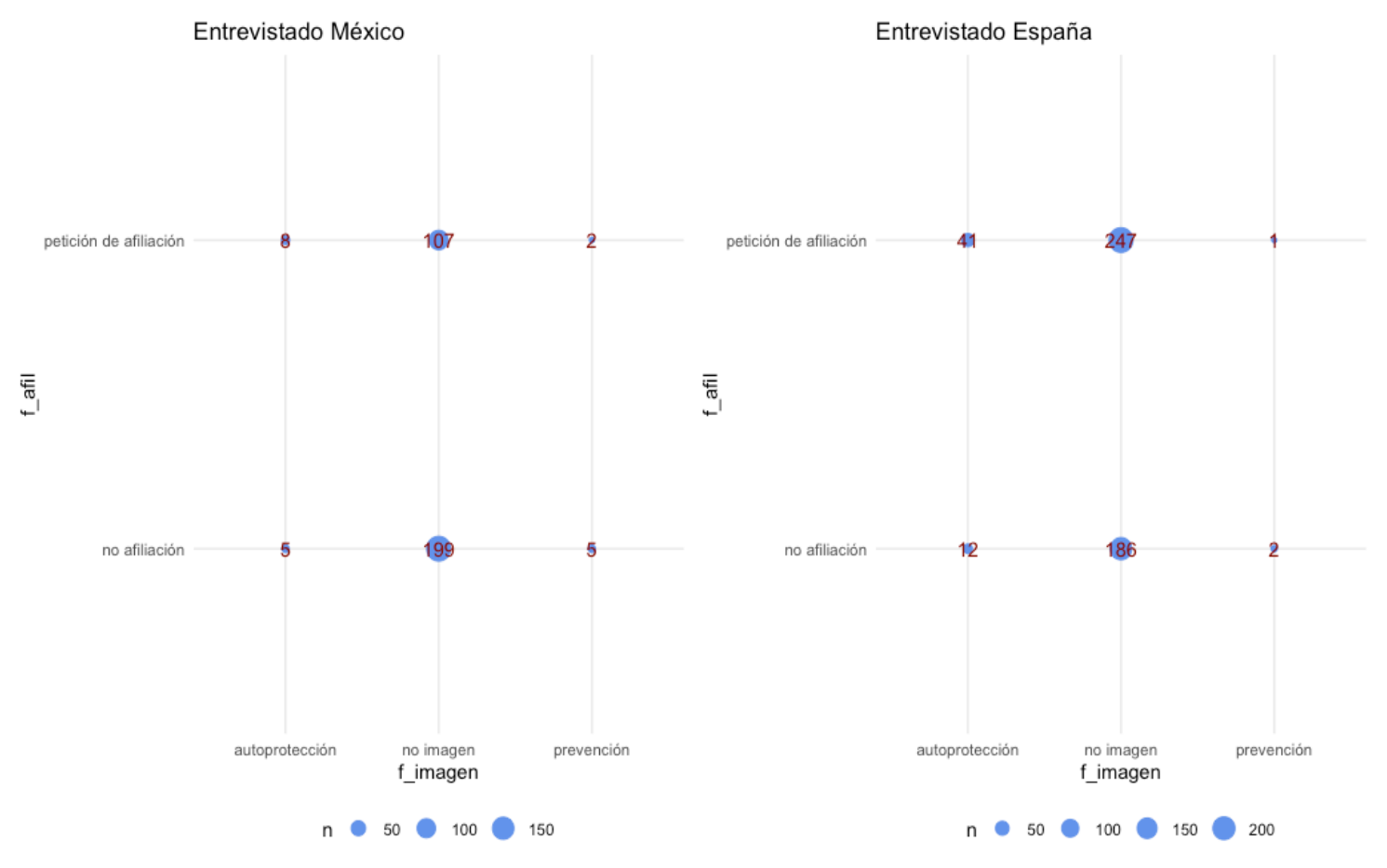

El papel del entrevistador en España y México (FIGURA 5) muestra patrones de distribución del marcador ¿no? distintos tanto entre países como respecto al papel discursivo de los entrevistados. Los datos de España muestran una clara preferencia de los entrevistadores por el uso de prevención de daños a la imagen sin afiliación, mientras que el resto de las combinaciones presentan una incidencia baja. En México el valor de prevención resulta asimismo el más frecuente. Sin embargo, se puede observar la prevalencia de la petición de afiliación, especialmente en conjunción con la prevención, pero también como estrategia única de gestión de la imagen. Por otra parte, la autoprotección (acompañada o no de petición de afiliación) y los valores de no afiliación e imagen cuentan con una incidencia muy limitada. 
Figura 5. Relación entre la atenuación y la petición de afiliación en entrevistadores

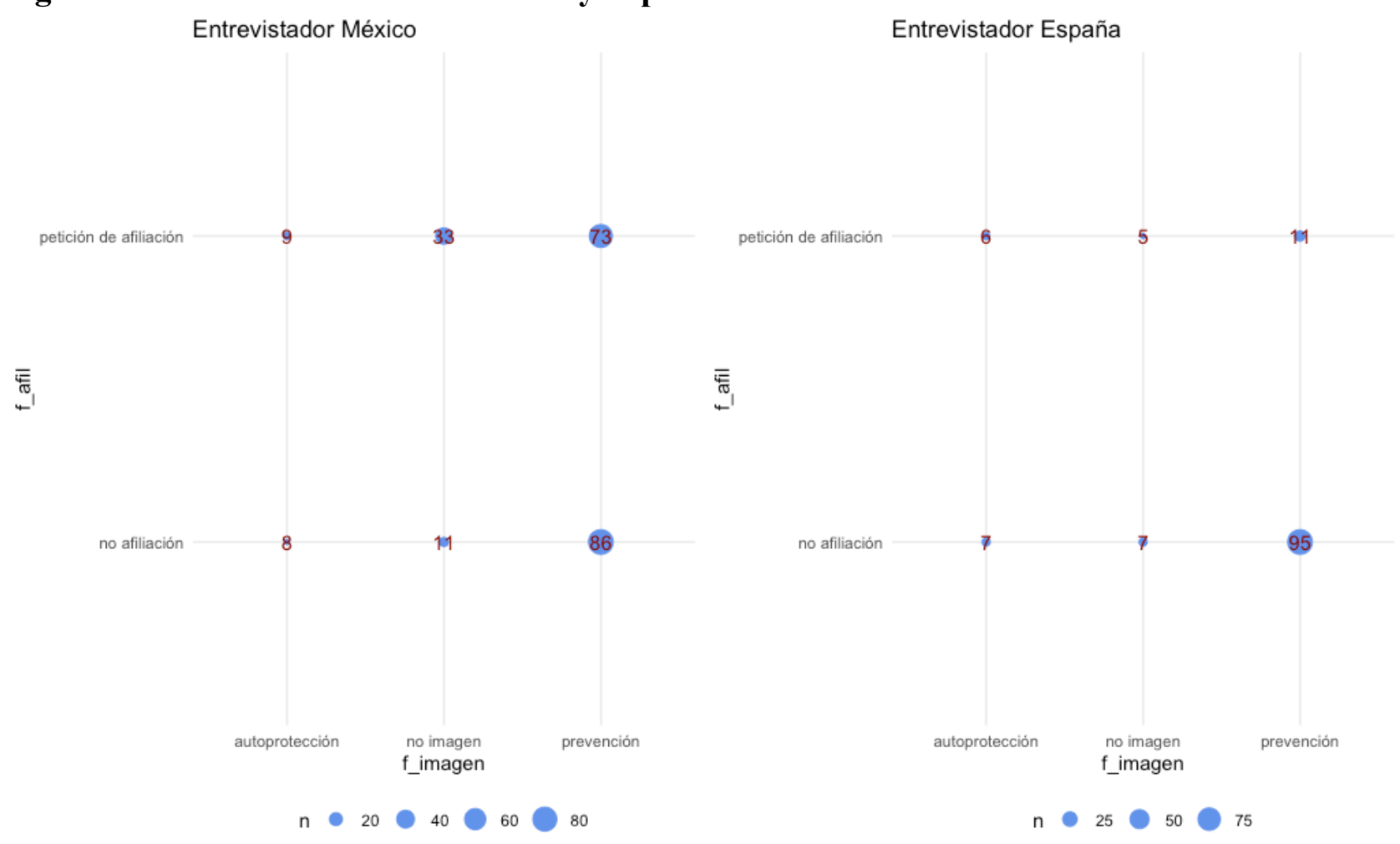

Como se detalla en las funciones atribuidas a ¿no? (sección 4.1.2), la intensificación se puede materializar mediante esta forma y puede emplearse tanto como estrategia de protección como de ataque a la imagen. Cuantitativamente, el uso de este marcador con una función intensificadora resulta muy limitado. De hecho, se registra únicamente en datos correspondientes a la conversación en España (en 5 de las 223 ocurrencias). De estas cinco instancias una corresponde a la autoprotección de la imagen y las cuatro restantes a una estrategia de ataque a la imagen.

\subsubsection{Estructuración de la información}

En esta sección se analizan los datos de las funciones de estructuración de la información de ¿no? en la conversación (Figura 6) y en la entrevista (Figura 7). En la conversación, el uso como movilizador de respuesta resulta más frecuente en México que en España, donde el valor mayoritario corresponde a su papel delimitador. Pese a esta ligera preferencia encontrada en los datos correspondientes a las dos variedades, la Figura 6 muestra que las dos funciones identificadas para la estructuración de la información (movilización de respuesta y delimitación) cuentan con un uso frecuente tanto en España como en México. 
Figura 6. Frecuencia de las funciones de estructuración de la información en la conversación por cada 1000 palabras

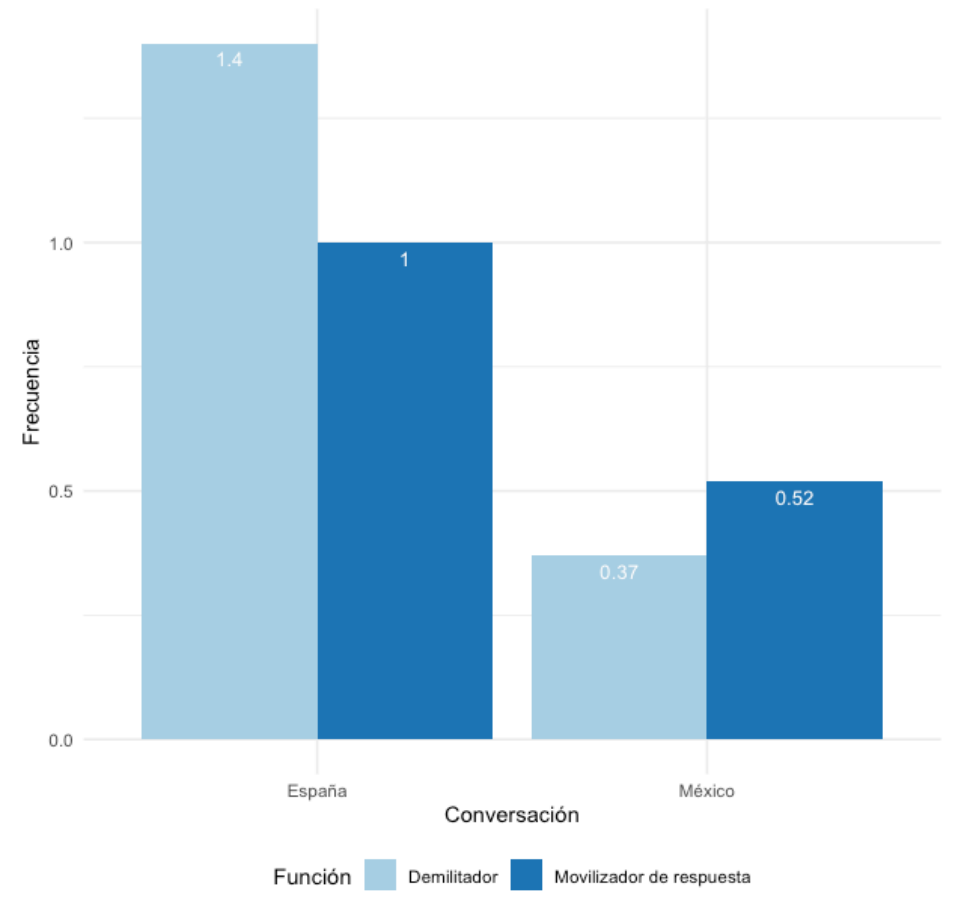

En el caso de la distribución de las funciones de estructuración de la información en la entrevista (FIGURA 7), se ha tenido en cuenta la distinción entre los papeles discursivos de este género: entrevistador y el entrevistado. Entre los entrevistados, la función predominante es la delimitadora, mientras que la movilización obtiene una frecuencia residual. En el caso de los entrevistadores, se observan tendencias opuestas entre el uso en España y México. La movilización de respuesta resulta la función más utilizada por los entrevistadores españoles, mientras que en el caso de los mexicanos se emplea mayoritariamente el valor delimitador. Sin embargo, aunque en menor medida, también se detecta un uso de la delimitación por los entrevistadores españoles y de la movilización de respuesta en los mexicanos. 


\section{Figura 7. Frecuencia de las funciones de estructuración de la información en la entrevista por cada 1000 palabras}

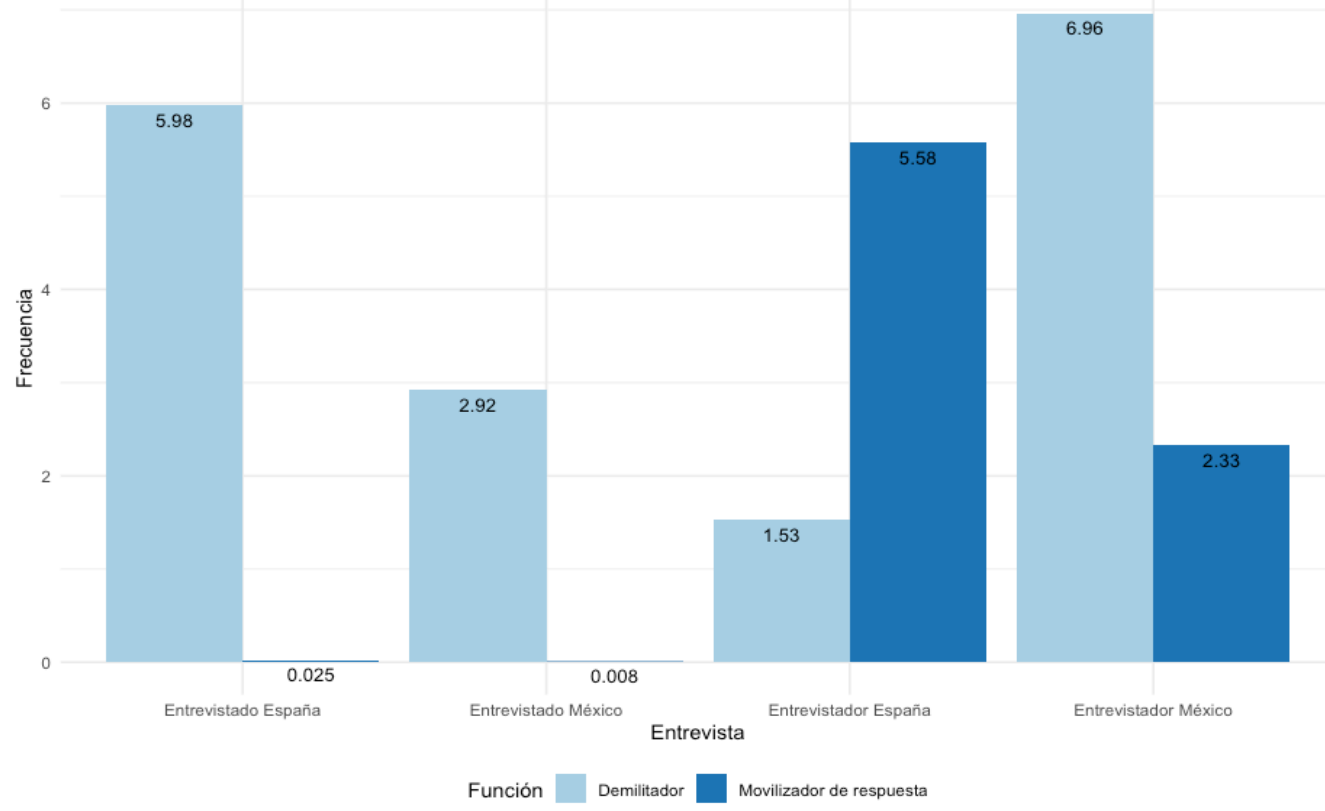

\section{DISCUSIÓN}

El análisis de ¿no? en los géneros de conversación y entrevista mediante datos del español de España y de México muestra que existen diferencias en la distribución, principalmente en el género discursivo, pero también en la variedad diatópica. En general, a partir de la muestra analizada, el uso de ¿no? parece ser más frecuente en España que en México. Sin embargo, ambos países coinciden en la tendencia a un uso más intensivo de este marcador en la entrevista que en la conversación. El aumento de la frecuencia en este género se debe tanto a la alta presencia de ¿no? en la parte de los entrevistadores (quienes cuantitativamente intervienen significativamente menos que los entrevistados), como al aumento de uso en la parte de las entrevistas que corresponde a los entrevistados.

En cuanto a la distribución funcional de ¿no?, los datos muestran la existencia de variabilidad tanto intergenérica como interdialectal. El uso de este marcador en la conversación como mecanismo de protección de la imagen y de petición de afiliación parece ser más frecuente en los datos de España que en los de México, donde se registra mayoritariamente sin funciones de imagen. Resulta llamativo el hecho de que el uso intensificador de ¿no? aparezca únicamente en la conversación española. Sin embargo, se debe tener en cuenta, por una parte, que el nivel de incidencia de este valor es muy bajo y, por otra parte, que precisamente los datos de la conversación mexicana presentan un número reducido de ocurrencias dedicadas a la gestión de la imagen. En cuanto a la estructuración de la información en la conversación, en México ¿no? tiene mayor incidencia como movilizador de respuesta, mientras que su uso como delimitador es más restringido. En España, la preferencia por estas dos funciones se invierte. Sin embargo, se debe tener en cuenta que el nivel de variación de estos valores es moderado y el uso como delimitador o movilizador de respuesta parece ser generalizado en los dos dialectos.

En la entrevista, se distingue el uso de ¿no? según el papel discursivo de entrevistador y el entrevistado, dado que existen entre ellos claras diferencias: en el caso 
de los entrevistados, las dos variedades dialectales coinciden en presentar una incidencia muy baja de estrategias de protección de la imagen a través de la atenuación. La razón parece encontrarse en que la entrevista sociolingüística persigue conseguir producción lingüística por parte de los entrevistados. Por tanto, como ya se apunta en un trabajo anterior (Uclés, 2018), los contextos en los que es necesaria la protección de la propia imagen resultan limitados y, como consecuencia, la incidencia de ¿no? atenuante con el fin de proteger la propia imagen es muy baja. Las funciones de atenuación orientada a la prevención de daños de la imagen de los interlocutores y, en el ámbito de la estructuración de la información, la función de movilización de respuesta tienen un uso residual en los entrevistados. En este caso se considera que precisamente el hecho de cumplir con su papel discursivo limita las situaciones en las que un entrevistado busca una respuesta de un interlocutor o produce un enunciado que pueda amenazar potencialmente la imagen del entrevistador (véase Uclés, 2018).

El empleo de ¿no? en entrevistadores sufre variaciones dialectales más profundas respecto a los datos de los entrevistados que, como se ha expuesto anteriormente, parecen ser más uniformes. En la estructuración de la información, los entrevistadores españoles muestran una clara preferencia por la movilización de respuesta, es decir, utilizan ¿no? con el fin de promover una respuesta por parte del entrevistado. El uso preferente de esta forma también puede proporcionar una explicación al hecho de que mayoritariamente las funciones de gestión de la imagen correspondan eminentemente a la prevención mediante la atenuación, puesto que los entrevistadores, al solicitar información u opiniones del entrevistado, provocan que el entrevistado desvele parte de su esfera privada, lo que puede suponer potencialmente una amenaza a la imagen de dicho entrevistado (Uclés, 2018). Estos datos serían los esperables, en tanto la función principal de los entrevistadores es estimular a los entrevistados para que produzcan información. Por tanto, el hecho de que los entrevistadores en México lo empleen mayoritariamente como delimitador resulta más remarcable. Así pues, los datos parecen apuntar a la existencia de una preferencia por parte de los entrevistadores mexicanos de hacer progresar la entrevista y, en última instancia, de recabar información más indirecta a través de ¿no? Al igual que en el caso de España, la presencia superior de la delimitación puede concebirse como una posible causa que explique los datos relativos a la gestión de información, puesto que las intervenciones en las que se encuentra ¿no? en los entrevistadores mexicanos no movilizan una respuesta pero sí contribuyen a que la interacción progrese. En muchas ocasiones este marcador se encuentra asociado con comentarios valorativos o de apoyo a lo dicho por el entrevistador. En este tipo de contextos, la forma ¿no? también se emplea con frecuencia para explicitar la solicitud de afiliación.

\section{CONCLUSIONES}

En los apartados precedentes, se ha llevado a cabo un análisis de las funciones de ¿no? en dos géneros discursivos y dos variedades diatópicas. De esta manera, las diferentes combinaciones según el dialecto, el género y el papel discursivo, en el caso de la entrevista, produce que se generen datos en los que se ha podido explorar la existencia de variabilidad distribucional que confirma, pero también matiza la caracterización de este marcador. Así, las conclusiones que se pueden establecer sobre el uso de ¿no? según el género responden a su comportamiento en dos variedades geográficas y las conclusiones sobre la variedad diatópica, a su vez, a su aparición en dos géneros. Este análisis doble permite poner de manifiesto la complejidad de la distribución del marcador, cambiante según género y dialecto. Sin embargo, el hecho de que los datos sean complejos no significa necesariamente que no se detecten patrones. A continuación, se 
desglosan las conclusiones generales respecto a esto tres ámbitos de estudio que se han explorado: el marcador ¿no?, el género discursivo y la variedad diatópica.

\subsection{CONCLUSIONES RESPECTO A ¿NO?}

En primer lugar, la aplicación de la tipología de funciones de ¿no? en datos que presentan una procedencia diversa en cuanto al origen geográfico y genérico permite valorar el grado de efectividad de esta propuesta metodológica. En esta clasificación se documenta una diversidad relativamente amplia en relación con los valores asociados a la gestión de la imagen que pone de manifiesto la versatilidad del marcador estudiado, así como la complejidad que entrañan los fenómenos ligados a la gestión interactiva. Adicionalmente, el hecho de aplicar un desarrollo teórico como la gestión de la protección de la imagen (Uclés, 2020b) a la descripción de un marcador evita descripciones ad hoc de las funciones del marcador. Esto resulta especialmente importante, puesto que permite homogeneizar los valores que se podrían emplear para el análisis de otras formas lingüísticas destinadas a la gestión de la interacción como pueden ser los marcadores a los que la bibliografía otorga una función fática o comprobativa (véase sección 2). En este sentido, la tipología propuesta en este trabajo potencialmente se puede concebir no solo como un instrumento exclusivo para la forma tratada en cuestión, sino como una plantilla de análisis para marcadores de naturaleza similar, es decir, aquellos que formalmente adoptan la forma interrogativa y apelan al interlocutor (¿sabes?, ¿eh?, ¿vale?, ¿me entiendes?, entre otros).

\subsection{CONCLUSIONES RESPECTO AL GÉNERO}

Si se analiza el comportamiento de ¿no? según el género discursivo, el dato más llamativo probablemente corresponde con su uso más frecuente en la entrevista respecto a la conversación. Esta tendencia, a priori, parece ir en contra de la idea de que, en tanto eminentemente interactiva, esta forma es debería encontrarse con mayor facilidad en situaciones donde haya un mayor nivel de interactividad, es decir, en la conversación coloquial (Briz, 1998). Sin embargo, por una parte, la configuración de los papeles discursivos del entrevistado y el entrevistador explica el uso elevado de este marcador y, por otra parte, en este género se detecta una alta especialización funcional de ¿no? en cada papel discursivo.

En concreto, los datos muestran que el papel del entrevistador acumula gran parte de las ocurrencias de ¿no? en este género (especialmente en las entrevistados procedentes de México). Como se ha expuesto anteriormente, este dato resulta todavía más llamativo por la disparidad en el número de palabras que se produce en ambos papeles: los entrevistados producen gran parte de las palabras de la entrevista, mientras que la intervención de los entrevistadores es cuantitativamente reducida (véase sección 3). Sin embargo, la razón se encuentra en que la función principal de los entrevistadores es guiar y hacer progresar la entrevista $\mathrm{y}$, en este sentido, el marcador ¿no? parece emplearse de manera altamente productiva precisamente con el fin de obtener una respuesta por parte de los entrevistados. Aunque parte del aumento de las ocurrencias de ¿no? se puede atribuir a los entrevistadores, también se detecta un mayor uso en los entrevistados respecto a la frecuencia en la conversación. En este caso, el uso prácticamente hegemónico de ¿no? con función delimitadora, esto es, dentro de los valores de la estructuración de la información, se explica porque las intervenciones de los entrevistados son más largas o monológicas que las intervenciones de la conversación y, por tanto, se genera una mayor necesidad de estrategias de estructuración del discurso. 
Dentro del género y relacionado con lo anterior, el rol discursivo es también condicionante para la mayor o menor incidencia de unas $u$ otras funciones. Así pues, en la entrevista, como ya se ha expuesto anteriormente, en el papel del entrevistado el uso de ¿no? está altamente especializado en la delimitación en cuanto a la estructuración de la información. Respecto a la protección de las imágenes, la función de prevención está altamente restringida en este papel, puesto que la desigualdad funcional impide que los entrevistados realicen acciones que puedan poner en peligro la imagen de los entrevistadores. Sucede lo contrario, en cambio, en el caso de los entrevistadores: la función de prevención de daños a la imagen parece acumular la mayor parte de las ocurrencias, dado que intentan que el entrevistado no se sienta atacado para que siga produciendo cómodamente el material lingüístico que pretenden conseguir. En cuanto al resto de valores de ¿no? en este papel, se detectan diferencias que parecen estar motivadas por preferencias dialectales (véase sección 7.3).

La conversación coloquial, por su parte, presenta una distribución de funciones más equilibrada, que parece alejarse tendencias de fuerte preferencia por uno o varios valores. En los datos de conversación en México cabe señalar, sin embargo, que en la mitad de las ocurrencias no se observan funciones de protección de la imagen. Esta afirmación no apunta a que la conversación mexicana no tenga en cuenta la protección de la imagen, sino a que lo hace mediante recursos distintos. Mientras que en la conversación española ¿no? es un marcador con mayor incidencia y altamente productivo para llevar a cabo funciones de protección de la imagen, en la conversación mexicana posiblemente se prefiere el uso de otros marcadores o estrategias lingüísticas, como la forma ¿verdad?, que se documenta con alta frecuencia en Monterrey en nuestro corpus de trabajo. En una línea similar, el estudio de San Martín (2011) muestra cómo la hegemonía de la partícula local ¿cachai? sitúa a resto de marcadores de control de contacto que analiza en una posición periférica respecto a su frecuencia de aparición y el análisis multidialectal de Santana (2017) también indica una frecuencia baja de ¿no? en Chile, Puerto Rico y Costa Rica. Se considera, por tanto, necesario un estudio global orientado a identificar en la conversación mexicana los elementos comprobativos, así como la manera en la que se gestiona la imagen.

\subsection{CONCLUSIONES RESPECTO A LA VARIEDAD DIATÓPICA}

Como se ha detallado en la sección anterior, los papeles discursivos de la entrevista parecen condicionar el uso de ¿no? de maneras específicas. Sin embargo, no toda la variación encontrada en este marcador se puede adscribir a la influencia del género. La variedad diatópica también parece ser responsable de parte las diferencias en el comportamiento de esta forma. En cuanto a la distribución de ¿no?, los datos indican que se emplea con mayor frecuencia en España que en México en los dos géneros analizados. Esta ventaja es especialmente acusada en la conversación, mientras que en la entrevista las frecuencias están más igualadas.

Respecto a la distribución de ¿no? según las funciones asignadas, se encuentran diferencias dialectales tanto en la conversación como en la entrevista. Los datos apuntan que la intensificación parece ser una función periférica en ¿no?, pero el reducido número de ejemplos procedente del corpus se registra exclusivamente en la variedad española y, específicamente, en la conversación. El hecho de que aparezca únicamente en la conversación puede adscribirse a su carácter confrontacional, puesto la intensificación se usa en cuatro de sus cinco ocurrencias como estrategia de ataque a la imagen del otro; mientras que, como es esperable, no hay apenas confrontación en la entrevista. Sin embargo, esta no es la única diferencia dialectal que se detecta en la conversación. Como 
mencionábamos en el apartado anterior, en los datos procedentes de la conversación mexicana la mayor parte de los ejemplos de ¿no? aparece sin funciones de gestión de imagen, empleado mayoritariamente como elemento de estructuración de la información En cambio, en la conversación española ¿no? cubre todo el espectro de funciones de gestión de la imagen y estas son las más abundantes.

Por último, en la entrevista, ¿no? muestra un comportamiento similar en los entrevistados de las dos variedades geográficas, mientras que en los entrevistadores sí existen diferencias de uso. En España se observa un uso mayoritario como movilizador de respuesta y estrategia de prevención, mientras que en México se prefiere la delimitación asociada a la petición de afiliación y la prevención. Estas dos tendencias muestran dos estilos diferentes de emplear el marcador para buscar la respuesta de los entrevistados. Mientras que en los entrevistadores españoles está asociado con un estilo más directo (de ahí la necesidad de prevenir daños en la imagen del interlocutor al buscar respuestas de forma más clara), los entrevistadores mexicanos acompañan y estimulan las intervenciones de los entrevistados de forma más indirecta a través de comentarios en los que, además de la prevención de daños a la imagen, se busca afiliación.

Las claras diferencias que arrojan los datos analizados en este estudio muestran la importancia de incluir la dimensión diatópica en el estudio de los marcadores del discurso. La variabilidad tanto en la frecuencia como en la distribución de las funciones de ¿no? en España y México pone de manifiesto que los estudios que tienen como base el español de España no representan necesariamente la realidad de uso más allá de en la variedad en la que se enmarcan. Como se ha apuntado anteriormente (sección 7.2), el desequilibrio cuantitativo y en cuanto al uso de ¿no? con valor de protección de la imagen en la conversación mexicana conduce a considerar que el aparente hueco funcional que se encuentra pueda ser rellenado por otras formas. Por tanto, este estudio muestra la necesidad fundamental de tener en cuenta la influencia de la variedad diatópica en el análisis tanto de elementos como de fenómenos pragmáticos (como es el caso de los marcadores del discurso y de la protección de las imágenes) para poder conseguir una panorámica completa del funcionamiento de la interacción.

\section{REFERENCIAS BIBLIOGRÁFICAS}

Albelda, Marta. 2004. «Cortesía en diferentes situaciones comunicativas: La conversación coloquial y la entrevista sociolingüística semiformal». En Pragmática sociocultural: Estudios sobre el discurso de cortesía en español, eds. D. Bravo y A. Briz. Barcelona: Ariel, 109-134.

Albelda, Marta. 2007. La intensificación como categoría pragmática: Revisión y propuesta: una aplicación al español coloquial. Frankfurt: Peter Lang.

Albelda, Marta. 2014. «Escalaridad y evaluación: Rasgos caracterizadores de la intensificación pragmática». En Emotionen, Expressivität, Emphase, eds. E. Pustka y S. Goldschmitt. Berlín: Eric Schmit Verlag, 79-94.

Albelda, Marta, y Estellés, Maria. (en prensa). «Mitigation revisited. An operative and integrated definition of the pragmatic concept, its strategic values and its linguistic expression». Journal of Pragmatics.

Brenes, Ester. 2011. «Recursos lingüísticos al servicio de la (des)cortesía verbal. Los apéndices apelativos». En Aproximaciones a la (des) cortesía verbal en español, eds. C. Fuentes, E. Alcaide y E. Brenes. Peter Lang, 119-137. https://doi.org/10.3726/978-3-0352-0055-3

Briz, Antonio. 1998. El español coloquial an la conversacion: Esbozo de pragmagramatica. Barcelona: Ariel. 
Cestero, Ana María. 2003. «El funcionamiento de los apéndices interrogativos en la conversación y en el discurso académico». En Decíamos ayer... Estudios en honor a María Cruz García de Enterría, eds. C. Castillo y J. M. Lucía. Alcalá de Henares: Universidad de Alcalá, 83-127.

Cestero, Ana María. 2019. «Apéndices interrogativos de control de contacto: Estudio sociolingüístico». Cuadernos de Lingüística de El Colegio de México, 6(1):1-65. https://doi.org/10.24201/clecm.v6i1.111

Fuentes, Catalina. 1990. «Apéndices con Valor Apelativo». En Sociolingüística andaluza 5: Habla de Sevilla y hablas americanas, eds. P. Carbonero Cano y M. T. Palet Plaja. Sevilla: Servicio de Publicaciones de la Universidad de Sevilla, 171-196.

Fuentes, Catalina. 2009. Diccionario de conectores y operadores del español. Madrid: Arco/Libros.

Fuentes, Catalina, y Brenes, Ester. 2014. «Apéndices apelativos en el lenguaje parlamentario andaluz: Variación pragmática». Oralia: Análisis del discurso oral, 17: 181-209.

García Vizcaíno, María José. 2005. «El uso de los apéndices modalizadores ¿no? Y ¿eh? en español peninsular». En Selected proceedings of the II Workshop on Spanish sociolinguistics, eds. L. Sayahi y M. Westmoreland. Somerville: Cascadilla Press, 89-101.

Landone, Elena. 2010. Los marcadores del discurso y cortesía verbal en español. Berna: Peter Lang. https://doi.org/10.3726/978-3-0351-0103-4

Móccero, María Leticia. 2010. «Las preguntas confirmatorias como indicadoras de posicionamiento intersubjetivo». Estudios Filológicos, 45: 67-78. https://doi.org/10.4067/S0071-17132010000100006

Montañez, Marta Pilar. 2008. «El apéndice ¿No? En la conversación coloquial española». Boletín de filología, 43 (2):117-174.

Montañez, Marta Pilar. 2009. «Marcadores del discurso y posición final: A propósito de “¿eh?”». Interlingüística, 19:110-121.

Montañez, Marta Pilar. 2015. Marcadores discursivos conversacionales y posición final. Hacia una caracterización discursiva de sus funciones en unidades del habla. Tesis doctoral, Universitat de València.

Ortega Olivares, Jenaro. 1985. «Apéndices modalizadores en español: Los 'comprobativos'». En Estudios románicos dedicados al profesor Andrés Soria Ortega, eds. J. Montoya y J. Paredes. Granada: Servicio de Publicaciones de la Universidad de Granada, 139-255.

R Core Team. 2019. R: A Language and Environment for Statistical Computing. Viena: R Foundation for Statistical Computing. https://www.R-project.org/

Rodríguez Muñoz, Franciso J. 2009. «Estudio sobre las funciones pragmadiscursivas de ¿no? Y ¿eh? en el español hablado». RLA. Revista de lingüistica teórica y aplicada, 47(1): 83-101. https://doi.org/10.4067/S0718-48832009000100005

San Martín, Abelardo. 2011. «Los marcadores interrogativos de control de contacto en el corpus PRESEEA de Santiago de Chile». Boletín de Filología, 46 (2):135-166. https://doi.org/10.4067/S0718-93032011000200006

Santana, Juana. 2017. «Marcadores interrogativos de interacción conversacional en la norma culta hispánica». Academia Boliviana de la Lengua, 232-287.

Santos Río, Luis. 2003. Diccionario de partículas. Salamanca: Luso-Española de Ediciones.

Stivers, Tanya. 2008. «Stance, Alignment, and Affiliation During Storytelling: When Nodding Is a Token of Affiliation». Research on Language y Social Interaction, 41(1):31-57. https://doi.org/10.1080/08351810701691123 
Stivers, Tanya., y Rossano, Federico. 2010. «Mobilizing Response». Research on Language $y \quad$ Social Interaction, 43(1): 3-31. https://doi.org/10.1080/08351810903471258

Uclés Ramada, Gloria. 2017. «La atenuación en Gandía Shore: los marcadores conversacionales ¿eh?, ¿no?, ¿sabes? y ¿vale?». En Atenuación e intensificación en géneros discursivos, eds. W. Mihatsch y M. Albelda. Iberoamericana Vervuert, 265-282.

Uclés Ramada, Gloria. 2018. «La atenuación de los marcadores de control de contacto en PRESEEA: un estudio comparativo entre España y México». Rilce, 34(3):1313-1335. https://doi.org/10.15581/008.34.3.1313-35

Uclés Ramada, Gloria. 2020a. «Epistemic (a)Symmetries and Mitigation in the Description of Conversational Markers: The Case of Spanish ¿no?». Corpus Pragmatics, 4(1): 107-131. https://doi.org/10.1007/s41701-019-00068-7

Uclés Ramada, Gloria. 2020b. «Mitigation and boosting as face-protection functions». Journal of Pragmatics, 169: 206-218. https://doi.org/10.1016/j.pragma.2020.09.017

Uclés Ramada, Gloria. 2020c. «Las funciones interactivas del marcador español ¿no? Las fronteras entre la atenuación y la protección de la imagen». Revista Signos, 53(104): 790-814. https://doi.org/10.4067/S0718-09342020000300790

Val.Es.Co, Grupo. 2003. «Un sistema de unidades para el estudio del lenguaje coloquial». Oralia: Análisis del discurso oral, 6: 7-61.

Val.Es.Co, Grupo. 2014. «Las unidades del discurso oral: La propuesta Val.Es.Co. de segmentación de la conversación (coloquial)». Estudios de Lingüística del Español, 35: 13-73.

Wickham, Hadley. 2016. ggplot2: Elegant Graphics for Data Analysis. Nueva York: Springer-Verlag. http://ggplot2.org 